DOI 10.17816/transsyst2018445-31

\author{
(C) M. Janić \\ Delft University of Technology \\ (Delft, Netherlands)
}

\title{
MULTICRITERIA EVALUATION OF THE HIGH SPEED RAIL, TRANSRAPID MAGLEV AND HYPERLOOP SYSTEMS
}

This paper presents the multicriteria evaluation of the High Speed Rail (HSR), TransRapid Maglev (TRM) and Hyperloop (HL) passenger transport system assumed to operate as the mutually exclusive alternatives along the given line/corridor. For such a purpose the methodology is synthesized consisting of the analytical models of indicators of performances of these systems used as the evaluation criteria and the multicriteria Simple Additive Weighting (SAW) method. Given the characteristics of infrastructure and rolling stock/fleet of vehicles/trains reflecting the systems' infrastructural and technical/technological performances, the indicators of operational, economic, environmental, and social performances are defined and modelled respecting the interests and preferences of the particular actors/stakeholders involved. These are users/passengers, the systems' transport operators, local, regional, and national authorities and investors, and community members.

The proposed methodology is applied to the line/corridor Moscow - St. Petersburg (Russia) by assuming that three HS systems exclusively operate there according to "what-if" scenario approach. The results indicate that, under given conditions, the HL is the preferable compared to the TRM and HSR alternative.

Keywords: High Speed Rail (HSR), Trans Rapid Maglev (TRM), Hyperloop (HL), multicriteria evaluation, methodology, indicators of performances, criteria

\section{INTRODUCTION}

Increasing of transport speed has been an endeavour for people for a long time. In general, due to the limitations on time and monetary budget in combination with permanent intention to maximise travel distances (i.e., territory), the high-speed at lower as possible costs have become crucial requests and later the main goal in developing innovative and new transport systems. Consequently the HS transport systems have been emerging. The already fully operational are High Speed Rail (HSR) and Air Passenger Transport (APT) [1]. In addition, the operational (China), under construction (Japan), and under consideration in many other countries, the forthcoming TransRapid Maglev (TRM), and particularly the most recent (still at the conceptual stage) Hyperloop (HL) system have joined the former two, the latest certainly as the completely new HS transport system. 
In general, the HS transport systems have been compared and evaluated by different approaches. Most of them have included listing and quantifying the internal and external performances and their comparisons in the absolute terms. Under such circumstances, the outcome has always indicated strength of one over the other considered systems with respect to the one and weakness respecting the other set of performances [2]. In addition, the potential investors, policy makers, political leaders, and the public have been presented the new systems by citing not only innovative but also other performances not unique to them, very often in the rather "promotional" way. More professional review of these unique performances carried out latter on has very often indicated that the promoted "advantages" of the new system(s) were actually not unique. Therefore, a rational comparison of the new systems compared to the existing ones based on a systematic evaluation of their major performances has had to be carried out. One of the approaches, in addition to the frequently used Cost-Benefit Analysis (CBA), has been application of the different multicriteria evaluation methods/techniques. These have enabled comparison of these systems as "packages" based on the selected indicators of their performances used as evaluation criteria $[3,4]$.

This paper deals with multicriteria evaluation of the HSR, TRM, and HL system serving users/passengers as the mutually exclusive alternatives along the given line/corridor. In some sense, this represents a continuation of the author's previous work on the multicriteria evaluation of the HS systems including HSR, TRM, and APT [3]. In addition to this introductory section, the paper consists of four other sections. Section 2 describes the main developments of particular HS systems. Section 3 describes the multicriteria evaluation methodology. This consists of the analytical models of indicators of the selected performances to be used as evaluation criteria, and the entropy method for estimating the relative importance, i.e., "weights" of particular criteria, and the SAW (Simple Additive Weighting) multicriteria method. Section 4 presents an application of the proposed methodology to the selected HS line/corridor between Moscow and St. Petersburg (Russia) in which three systems are assumed to operate as mutually exclusive alternatives according to "what-if" scenario approach. The last section comprises some main conclusions.

\section{DEVELOPMENTS OF THE HIGH SPEED (HS) TRANSPORT SYSTEMS}

\subsection{The High Speed Rail system}

The High Speed Rail (HSR) systems have been developing worldwide (Europe, Far East-Asia, and USA as the rather innovative HS transport systems 
within the railway-based transport mode. Despite the common name, different definitions of these systems have been used in the particular world's regions. In Japan, the HSR system is called "Shinkansen" (i.e., 'new trunk line') at which trains can operate at the speeds of at least and above $200 \mathrm{~km} / \mathrm{hr}$. The "Shinkansen" system's network has been built with the specific technical standards (i.e., dedicated tracks without the level crossings and the standardized and special loading gauge). In Europe the HSR system including compatibility of infrastructure and rolling stock enables operating speeds equal or greater than $250 \mathrm{~km} / \mathrm{h}$ (Category I). In China, according to Order No. 34, 2013 from the China's Ministry of Railways, the HSR system (Its specific acronym is - China Railway High (CRH)) refers to the newly built passenger dedicated lines with (actual or reserved) speed equal and/ or greater than $250 \mathrm{~km} / \mathrm{h}$. In the USA, the HSR system is defined as that providing the frequent express services between the major population centers on the distances from 321.8 to $965.4 \mathrm{~km}$ with a few intermediate stops, at the speeds of at least $241.35 \mathrm{~km} / \mathrm{h}$ ). This to be carried out on the completely grade-separated, dedicated rights-of-way lines [5-7] of the cross-section of the HSR line.

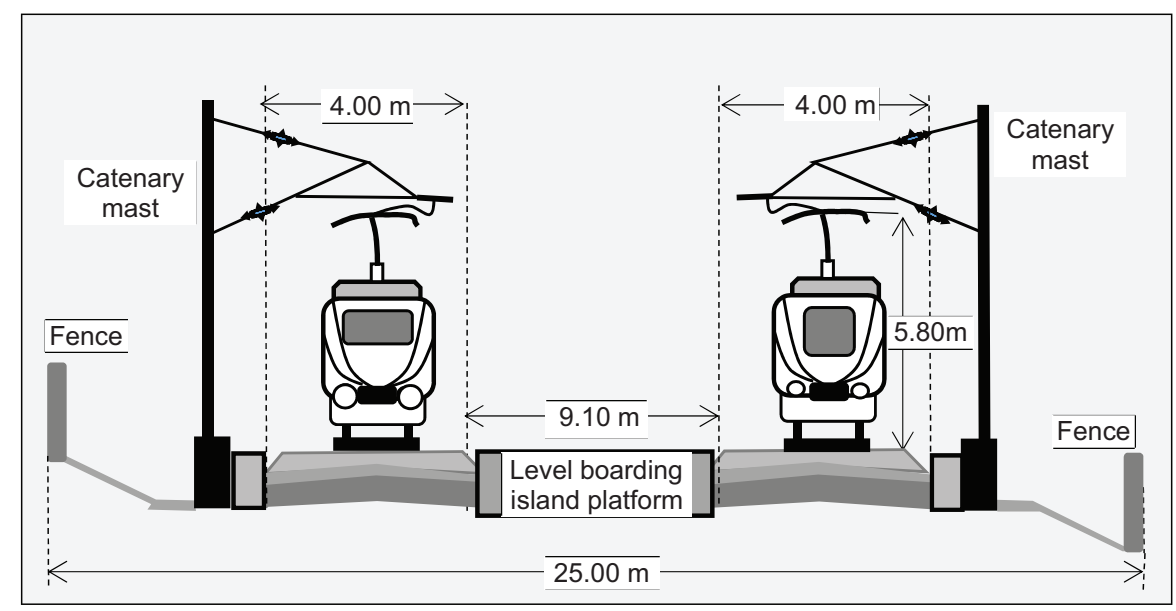

Fig. 1. Scheme of the right-of-way of the HSR systems [8]

\subsection{The TransRapid Maglev system}

The TransRapid MAGLEV (TRM) as the High Speed (HS) system is based on the Herman Kemper's idea of magnetic levitation dated from 1930s. The magnetic levitation enables suspension, guidance, and propelling the TRM vehicles by magnets rather than by the mechanical wheels, axles, and bearings as its HSR wheel/rail counterpart. Two forces - lift and thrust or propulsion - both created by magnets are needed for operating the TRM vehicle. Although TRM system has been matured to the level of commercialization, its infrastructure has only been 
fragmentary built, mainly connecting the airport (s) with the city centers, which is still far from development of the network similarly as that of the High Speed Rail (HSR) $[1,9,10]$. Table 1 gives some time milestones of developing the TRM system.

Table 1. The time milestones of developing TransRapid MAGLEV system [1, 11]

\begin{tabular}{|l|l|}
\hline $1970 \mathrm{~s}$ & The research on the Maglev transportation had been intensified (Japan, Germany). \\
\hline 1977 & $\begin{array}{l}\text { The first TRM (TransRapid Maglev) test line of the length of } 7 \mathrm{~km} \text { had been built } \\
\text { (the test speed achieved was: } 517 \mathrm{~km} / \mathrm{h} \text { ) (Japan). }\end{array}$ \\
\hline 1993 & $\begin{array}{l}\text { The TRM test of } 1674 \mathrm{~km} \text { had been carried out (the achieved speed was: } 450 \mathrm{~km} / \mathrm{h} \text { ) } \\
\text { (Germany). }\end{array}$ \\
\hline $1990 /$ & $\begin{array}{l}\text { The Yamanashi TRM test line of the length of } 42.8 \mathrm{~km} \text { had been constructed in the } \\
\text { year } 1990 \text { and the first test carried out in the year } 1997 \text { (EDS - Electro Dynamic } \\
\text { Suspension) (Japan). }\end{array}$ \\
\hline 2004 & $\begin{array}{l}\text { The first TRM line between Shanghai and its Pudong International airport (China) } \\
\text { was built and commercialized (Length of line: } 30 \mathrm{~km} \text {; } \\
\text { Average travel time: } 7.33 \text { min; Average speed: } 246 \mathrm{~km} / \mathrm{h} \text {; Transport service } \\
\text { frequency: } 4 \text { dep/h. }\end{array}$ \\
\hline
\end{tabular}

In addition, Fig. 2 shows the simplified scheme of the right-of-way of the TRM line.

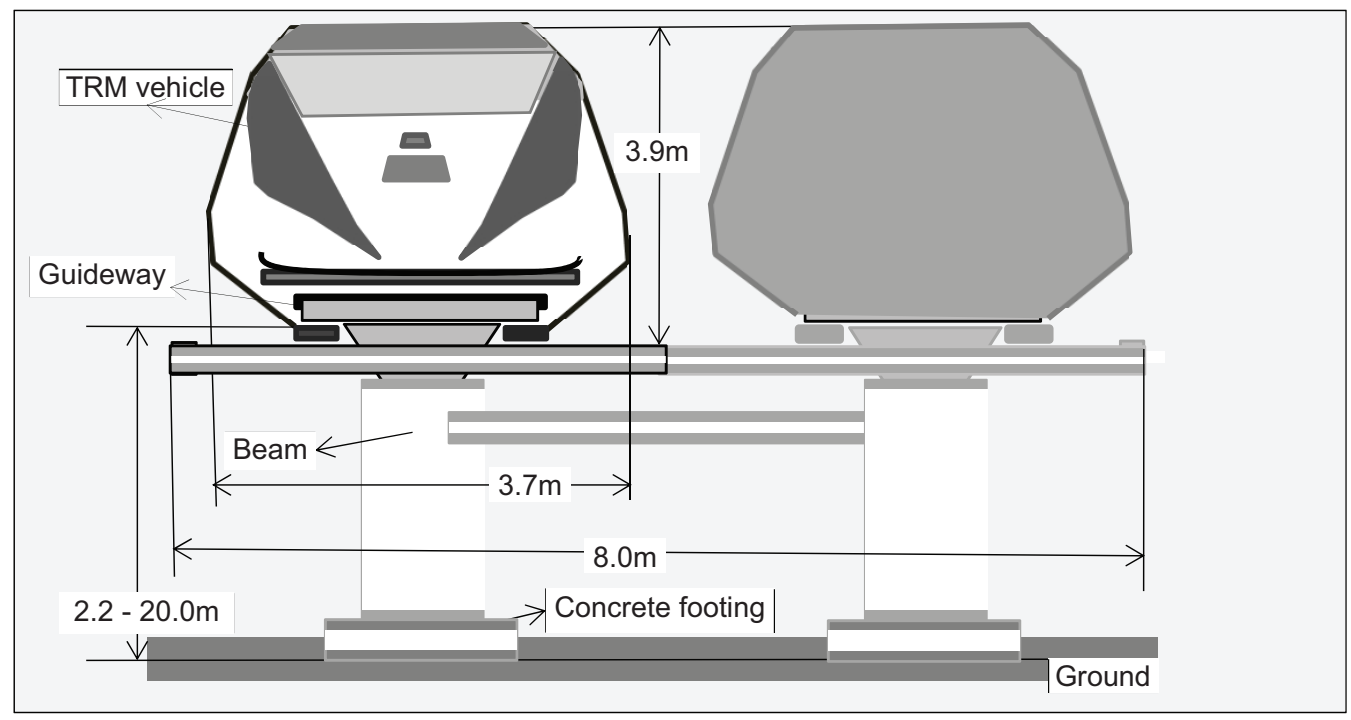

Fig. 2. Scheme of the right-of-way of the TRM system [1]

\subsection{The Hyperloop system}

The Hyperloop (HL) is the newest HS transport system currently in the conceptual stage. It is claimed to be with the superior operational, economic, 
environmental, and social performances particularly compared to those of HSR system $[12,13]$. However, these are still to be eventually confirmed after an initial commercialization of the system. The main components of HL system are:
a) Infrastructure;
b) Rolling stock/capsules;
c) Supporting facilities and equipment.
a) Infrastructure

The main infrastructure of the HL system includes the vacuumed tubes with the stations along them enabling operations of the HL rolling stock/vehicles/ capsules. The tubes are the steel-made with the wall thickness of 20 and $30 \mathrm{~mm}$ and the diameter of $2.23 \mathrm{~m}$ for the version "Hyperloop Passenger Capsule" and $3.6 \mathrm{~m}$ for the version "Hyperloop Passenger Plus Vehicle Capsule". They are positioned on the elevated pillars, which would be approximately at the distance for $30 \mathrm{~m}$ except for tunnel and bridge sections. The ultra-high vacuum of about 0.75 Torr) $(0.015$ psi or $100 \mathrm{~Pa})$ (British and German standards; Torr $=$ Toricheli) would be maintained in the tube (the standard aatmospheric pressure amounts 760 Torr or $1.01310^{5} \mathrm{~Pa}$ ). The scheme of the right-of-way of the "Hyperloop Passenger Capsule" version is shown on Fig. $3[12,13]$.

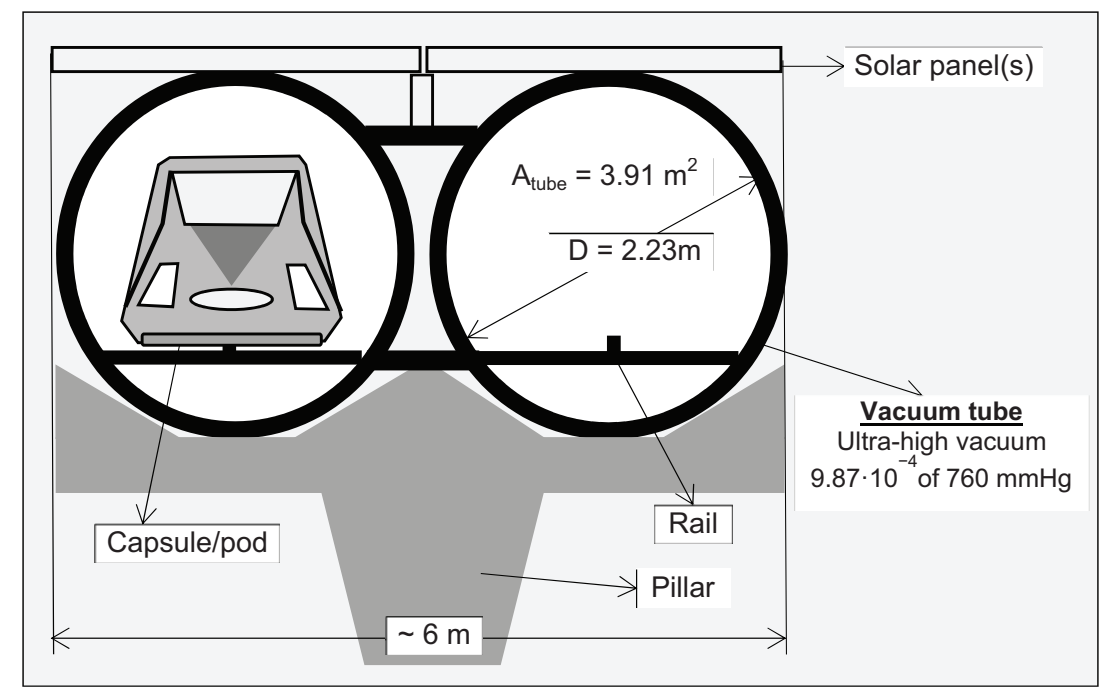

Fig. 3. Scheme of the right-of-way of the version "Hyperloop Passenger Capsule"

The stations of HL system would consist of three modules integrated within the tubes. The first is the chamber, which as a part of the vacuum tube handles the arriving HL capsule (ultimately the 'arriving' chamber). After entering the capsule, the chamber is de-vacuumed. Then, the capsule proceeds to the second module with the normal atmospheric pressure where passengers embark and/or disembark 
it. After that, the capsule passes to the third chamber where at that moment the normal atmospheric pressure prevails (ultimately the 'departing' chamber). Then it spends time until the chamber is de-vacuumed, leaves it, and proceeds along the tube. This handling process of a capsule takes place at each station of the line.

The chambers are separated by the hermetic doors enabling establishing and maintaining the required air pressure in the above-described order [12].

b) Rolling stock/capsules

The rolling stock/capsules of the HL system operate within the abovementioned vacuum tubes. Their size is adapted to the diameter of the tubes. Consequently, the frontal area of the version "Hyperloop Passenger Capsule" is $1.4 \mathrm{~m}^{2}$ and that of the version "Hyperloop Passenger Plus Vehicle Capsule" is $4.0 \mathrm{~m}^{2}$. They are supposed to "float" on a $0.5-1.3 \mathrm{~mm}$ layer of air featuring the pressurized air and the aerodynamic lift. Under such conditions, they will be able to operate at the maximum cruising speed of up to $1.220 \mathrm{~km} / \mathrm{h}$ (the maximum acceleration is going to be higher than that of HSR, TRM, and commercial aircraft - about $1.5 \mathrm{~m} / \mathrm{s}^{2}$. The total (gross) weight of each capsule including its own, passenger, and luggage is planned to be $15000 \mathrm{~kg}$ for "Passenger" and $26000 \mathrm{~kg}$ for "Passenger Plus Vehicle" version, with the capacity of 28 seats/unit. The required aerodynamic power at the speed of $1120 \mathrm{~km} / \mathrm{h}$ is supposed to be about $285 \mathrm{~kW}$ with the drag force of $910 \mathrm{~N}$ (KW - Kilowatt; N - Newton). Fig. 4 shows the simplified scheme of the "Hyperloop Passenger Capsule" $[12,13]$.

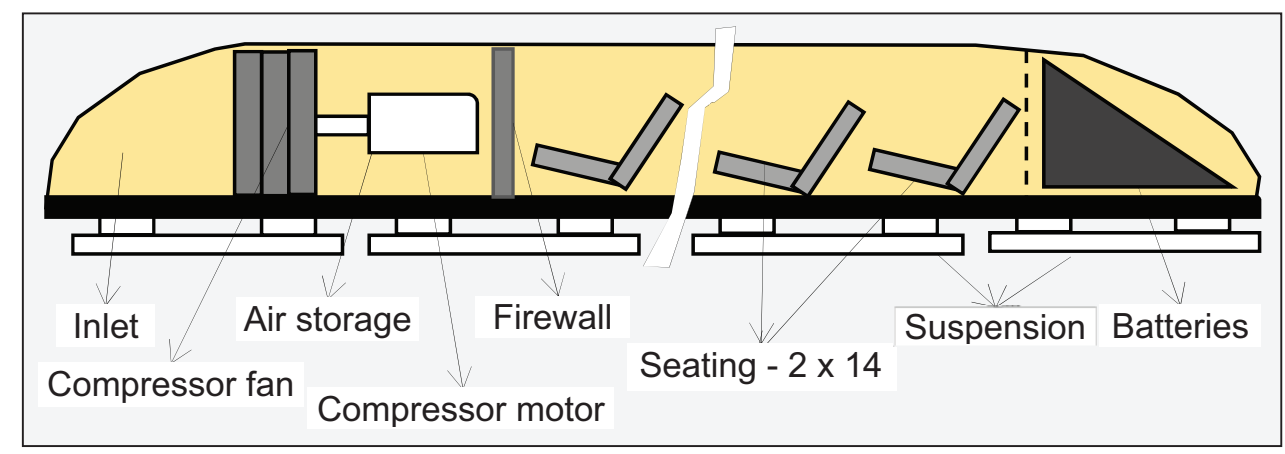

Fig. 4. Simplified scheme of "Hyperloop Passenger Capsule" [12]

c) Supporting facilities and equipment

The main supporting facilities and equipment are:

i) Power supply system;

ii) Vacuum;

iii) Vehicle and traffic control and management system. In addition, these are the maintenance systems for the previously mentioned components $[12,13]$. 


\section{i) Power supply system}

The power supply system is based on the solar panels installed on the vacuum tubes, which collect the sun energy. This is then converted into the electric energy used by the supporting facilities and equipment and rolling stock/capsules [12].

\section{ii) Vacuum pumps}

The vacuum pumps are installed to initially evacuate and latter maintain the required level of vacuum inside the tubes and at the stations' first and third chambers. Creating vacuum within the tube implies an initially large-scale evacuation of air and later on removal of the smaller molecules near the tubes' walls using the heating techniques. These pumps would consume a rather substantive amount of energy. They would be located along the tube(s) in the required number depending on the volumes of air to be evacuated, available time, and their evacuation capacity. In addition, de-vacuuming and vacuuming chambers at the stations, the required number of vacuum pumps will operate accordingly $[12,13]$.

\section{iii) Vehicle and traffic control/management system}

This system within the tubes and at the stations mainly embraces switches, sidings, and airlocks. The switches will enable the vehicles to pass them at the maximum speed in all directions. With such switches, the vehicles with different destinations will not interfere with each other. The sidings located approximately at every $10 \mathrm{~km}$ along the tubes consist of the low speed switches and airlocks allowing evacuation of the users/passengers in cases of the serious technical failures. The airlocks are devices equipped with the gate valves allowing efficient boarding and disembarking of users/passengers inside the vacuum tube without the need to vent it entirely $[12,13]$.

\section{A METHODOLOGY FOR MULTICRITERIA EVALUATION OF THE HS TRANSPORT SYSTEMS}

\subsection{Literature review}

In the given context, it can be said that an enormous amount of the academic and consultancy research has been dealing with the HS transport systems. This can be divided into that analysing the systems themselves, their comparison, and the (multicriteria) evaluation. Some rather limited examples of analysing the systems themselves have included the HSR systems, which have also been often implicitly compared with Air Passenger Transport (APT) as the potential competitor on the short-to medium-long distances/routes $[2,5,6,7,14]$. The similar approach has been applied to analysing the TRM system $[1,15]$. The concept of HL has been elaborated with mentioning its prospective advantages as compared to HSR and TRM system [12]. The illustrative cases of comparison of the particular HSR 
systems have related to HSR and TRM [4, 9], as well as to HL and TRM [13]. An example of the multicriteria evaluation of the HSR, TRM, and APT has been the past author's work [12]. In certain sense, the present paper represents a continuation of the latest-mentioned author's work, but this time dealing with the multicriteria evaluation of three ground-based HS systems.

\subsection{Objectives}

The objectives of this paper are to synthesize a methodology for the multicriteria evaluation of three HS transport systems - HSR, TRM, and HL, serving users/passengers as the mutually exclusive alternatives along the given line/corridor. Consequently, the proposed methodology includes the multidimensional examination of their performances, development of the analytical models of indicators of performances for their quantification and use as the evaluation criteria, the entropy method for assessing their relative importance (i.e., weights) for the prospective DMs, and the Simple Additive Weighting (SAW) multicriteria evaluation method. Therefore, the main contributions of the research can be considering:

- Multidimensional examination of performances and development of the analytical models of their indicators respecting preferences of particular actors/ stakeholders involved as the prospective DMs;

- Application of the proposed methodology to the real-life transport/corridor where three systems area assumed to exclusively operate according to "what-if" scenario approach.

\subsection{The concept of performances}

The considered performances of the above-mentioned three HS systems in the multicriteria evaluation are operational, economic, environmental, and social. They are dependent on the technical/technological characteristics of the systems' infrastructure and rolling stock/fleet of vehicles. The simplified scheme is shown on Fig. 5.

In general, the technical/technological characteristics of the HS systems' infrastructure relate to their lines, the stops along the lines, and the stations/ terminals at their ends. Those of the rolling stock/fleet of vehicles relate to its/ their type and space (seats and standings) capacity including the energy powering them. In addition, these are the characteristics of power supply and traffic control system, the latter including the traffic signalling system with components located along the HS lines and on board the rolling stock/fleet of vehicles. In addition: 


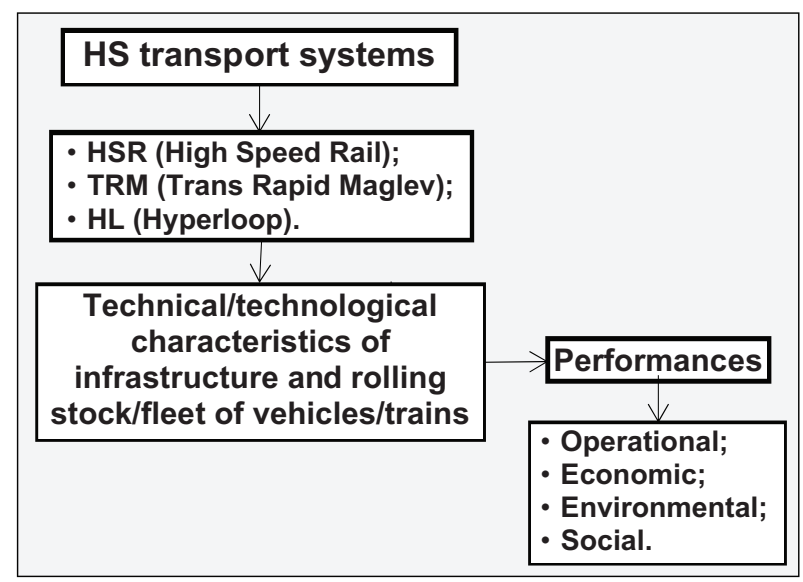

Fig. 5. Scheme of the considered performances of the HS systems

a) Operational performances are represented by the indicators such as:

i) Size of rolling stock/fleet of vehicles influenced by the volumes of user/ passenger demand to be served, the required transport service frequency, and the turnaround time along the given HS line/corridors;

ii) Transport work;

iii) Technical productivity;

iv) Load factor of rolling stock/fleet of vehicles. As such, they are mostly relevant for transport operators, i.e., providers/suppliers of transport infrastructure and services.

b) Economic performances are represented by the indicators such as:

i) Operating $\operatorname{costs}^{1}$ of a given HS system;

ii) Generalized travel costs of users/passengers;

iii) Welfare expressed by savings in the generalized travel costs of users/ passengers if switching from the existing (lower speed) to one of three considered (higher speed) alternatives. They are mostly directly relevant for transport operators, i.e., providers/suppliers of transport infrastructure and services, users/passengers, and indirectly entire society.

${ }^{1}$ These generally include: i) Direct (train movement costs), ii) Commercial costs of customer services (non-direct costs), and iii) Other costs for the infrastructure use. The first embrace the costs of train ownership, rolling stock maintenance and cleaning, energy, operating personnel, and the marginal cost of infrastructure (covering its costs of investments and capital maintenance). The second includes the costs of distribution (sales) and access control, passenger services, advertising, general and structural, and working capital costs and bank and credit charges. The last include station and security charges and infrastructure charges above marginal costs [27]. 
c) Environmental performances are expressed by the indicators such as:

i) Energy/fuel consumption and corresponding emissions of Green House Gases (GHG);

ii) Land use;

iii) Waste (This latest is not particularly considered). They are mainly relevant for local communities, authorities at different levels, transport operators, and entire society.

d) Social performances are expressed by the following indicators:

i) Noise;

ii) Congestion;

iii) Traffic incidents/accidents (i.e., safety). They are mainly relevant for local communities, authorities at different levels, transport operators, and entire society.

At the environmental and social performances, the selected indicators express only direct impacts without considering their costs - externalities.

\subsection{Modelling the indicators of performances}

\subsubsection{Assumptions}

The models of above-mentioned indicators of performances of the three HS systems are based on the following assumptions:

- Each system operates along the given line/corridor as an exclusive HS alternative; this implies that competition between systems is not considered;

- Each system takes over the entire volumes of user/passenger demand, i.e., it is assumed to have $100 \%$ market share;

- The volumes of user/passenger demand enable supply of transport service capacity up to the level of capacity of infrastructure - line and stations along it;

- The marginal contributions to GDP are equivalent to those of the current averages of the rail passenger transportation;

- Accessibility of all three systems from the corresponding urban areas is equivalent since their begin-end stations/terminals are assumed to be at the identical locations.

\subsubsection{Operational performances}

The main indicators of the operational performances are considered to be:

a) Required rolling stock/fleet of vehicles;

b) Transport work;

c) Technical productivity;

d) Load factor of the rolling stock/fleet of vehicles. 


\section{a) Required rolling stock/fleet of vehicles}

The size of rolling stock/fleet of vehicles is expressed by the number of trains of the given space capacity required to operate under conditions usually characterized by the transport service frequency carried out during a given period of time (h, day) and the trains' turnaround time along the given line/corridor. This required number of rolling stock/vehicles/trains can be estimated as follows $[1,16]$ :

$$
R R S(\tau)=f(\tau) \times \tau_{l},
$$

where $f(\tau)$ is the transport service frequency scheduled along the line/corridor during the time $(\tau)(\mathrm{dep} / \mathrm{h}$ or dep/day); $\tau$ is the time during which the transport services are scheduled ( $1 \mathrm{~h}$ or $24 \mathrm{~h})(\mathrm{h}-\mathrm{hour})$; and $\tau_{l}$ is the average turnaround time of a train along the line/corridor (min, $h$ ).

The transport service frequency $f(\tau)$ in Eq. 1a can be estimated as follows $[8,16]$ :

$$
f(\tau)=\min \left[\mu_{l}(\tau) ; \mu_{s}(\tau) ; Q(\tau) /(\theta(\tau) \times \Delta S)\right],
$$

where $\mu_{l}(\tau)$ is the traffic capacity of the line/corridor (trains/h or trains/day); $\mu_{s}(\tau)$ is the traffic capacity of the stations/terminals along and both ends of the line/ corridor (trains/h or trains/day); $Q(\tau)$ is the expected volumes of user/passenger demand on the line/corridor during the time $(\tau)$ (pax/h or pax/day per dir) (pax passenger(s); dir-direction); $\theta(\tau)$ is the average load factor of the trains scheduled on the line/corridor during the time $(\tau)(\theta(\tau) \leq 1.0) ; S$ is the space capacity of a train (sp/vehicle/train) (sp - space: seats and standings).

Eq. $1 \mathrm{~b}$ implies that all trains scheduled on the line/corridor are of the same space capacity. In addition, the transport service frequency cannot be higher than the traffic capacity of the line and the stations along it including begin and end station/terminal.

The average turnaround time of a train $\left(\tau_{l}\right)$ along the line/corridor in Eq. 1a is estimated as follows:

$$
\tau_{l}=\tau_{o}+2 \times \Delta \tau_{l}+\tau_{d},
$$

where $\tau_{o}, \tau_{d}$ is the average turnaround time of a train at the begin and end station of a line, respectively $(\mathrm{min}) ; \Delta \tau_{l}$ the train's operating time along the line/corridor in single direction $(\mathrm{min} ; \mathrm{h})$.

$$
R R S(\tau)=f(\tau) \times \Delta \tau_{l}
$$

In Eq. 1c, the train's turnaround time $\left(\tau_{l}\right)$ increases with increasing of the operating time along the line (the ratio between the length of line/route and the 
operating speed), the number and duration of intermediate stops, all in both directions including those at the begin and end station/terminal, and vice versa.

The train's operating time along the line/corridor $\left(\Delta \tau_{l}\right)$ in Eq. 1c can be estimated as follows:

$$
\Delta \tau_{l}=\sum_{k=1}^{K-1}\left(\frac{l_{k}}{v_{k}}+\frac{v_{k}}{a_{k}}\right)+\sum_{k=1}^{K-2} \tau_{s / k} \text { and } L=\sum_{k=1}^{K-1} l_{k},
$$

where $K$ is the number of intermediate stations along the line/corridor where the trains stop including the begin and end terminal; $v_{k}$ is the operating speed of a train along the $(k)$-th interstation segment of the line $(\mathrm{km} / \mathrm{h}) ; a_{k}$ is the average train's acceleration/deceleration rate along the $(k)$-th interstation segment of the line $\left(\mathrm{m} / \mathrm{s}^{2}\right) ; \tau_{s / k}$ is the time of a train stop at the $(\mathrm{ki})$-th intermediate station of the line/corridor ( $\mathrm{min})$; $L$ is the length of line/corridor consisting of $(K-1)$ segments between the intermediate stations $(\mathrm{km}) ; l_{k}$ is the length of the $(k)$-th interstation segment of the line/corridor $(\mathrm{km})$.

b) Transport work

The transport work of the given line/corridor can be estimated for the supply and demand side. On the supply side, it counts the total offered number of spaces during a given period of time. On the demand side, it counts the total number of used spaces under the same conditions. Based on Eq. 1c, the transport work on a given line for the supply side and demand in terms of ( $\mathrm{s}-\mathrm{km} / \mathrm{h}$ ) (seat-kilometres per hour) and ( $\mathrm{p}-\mathrm{km} / \mathrm{h})$ (passenger-kilometres per hour), respectively, is estimated as follows [16]:

$$
T W_{1}(\tau)=f(\tau) \times \Delta S \times \Delta L ; T W_{2}(\tau)=f(\tau) \times \Delta \theta \times \Delta S \times \Delta L,
$$

where all symbols are analogous to those in the previous Eqs.

As can be seen, the transport work increases with increasing of the length of line, transport service frequency, the train's space capacity and load factor, and vice versa.

c) Technical productivity

The technical productivity of the given line/corridor at both supply and demand side expressed by the volumes of seat $-\mathrm{km} / \mathrm{h}^{2}$ and $\mathrm{p}-\mathrm{km} / \mathrm{h}^{2}$, respectively, is estimated as follows [16]:

$$
T P_{1}(\tau)=f(\tau) \times \Delta S \times \Delta \bar{v} \text { and } T P_{2}(\tau)=f(\tau) \times \Delta S \times \Delta \theta \times \Delta \bar{v},
$$

where all symbols are analogous to those in the previous Eqs.

From Eq. 3, the technical productivity increases with increasing of the transport service frequency, the train space capacity, load factor, and the average operating speed, and vice versa. 
d) Load factor

The load factor reflects the utilisation of the capacity of rolling stock/fleet of vehicles serving the expected volumes of user/passenger demand during a given period of time. From Eq. 1b, the average load factor is as follows:

$$
(\theta(\tau)=Q(\tau)) /[f(\tau) \times \Delta S],
$$

where all symbols are analogous to those in Equation $1 \mathrm{~b}$.

\subsubsection{Economic performances}

The indicators of economic performances are considered to be:

a) Operating costs;

b) Generalized user/passenger travel costs;

c) Users/passengers "welfare" in terms of savings in the generalized travel costs if switching from the existing (lower speed) to one of three considered (higher speed) alternatives;

d) Contribution to Gross Domestic Product (GDP).

a) Operating costs

The operating costs can be expressed by the total and the average amounts.

i) Total costs

The total costs of the given system infrastructure and transport services during the given period of time (i.e., usually 1 year) can be expressed as follows:

$$
C=C_{F}+C_{V},
$$

where $C_{F}$ is the fixed cost of depreciation and capital maintenance, and administration of the given system's infrastructure and rolling stock/fleet of vehicles-trains during the given period of time (year) (\$US or $€$ per year); $C_{V}$ is the operating costs of infrastructure (regular maintenance) and/or of the rolling stock/fleet of vehiclestrains (energy, maintenance, staff, infrastructure charges) during the given period of time (\$US or $€$ per year).

ii) Average costs

The average costs per unit of input (\$US or $€ /$ space-km) and/or per unit of output ( $\$ U S$ or $€ / \mathrm{p}-\mathrm{km})$, respectively, are equal to:

$$
\bar{c}_{i}=\frac{C_{T}}{365 \cdot \tau \cdot f(\tau) \cdot S \cdot 2 L} \text { and } \bar{c}_{0}=\frac{C_{T}}{365 \cdot \tau \cdot f(\tau) \cdot \theta \cdot S \cdot 2 L},
$$

where all symbols are analogous to those in the previous Eqs.

Equation $4(a, b)$ suggests that the average cost per unit of output decreases with increasing of the volume of its output during a given period of time. 
b) Generalized user/passenger costs

The generalized user/passenger cost along the given line/corridor can be estimated as follows:

$$
\operatorname{cg}(\tau)=\alpha \times \Delta\left[S D(\tau)+\Delta \tau_{l}\right]+P,
$$

where $\alpha$ is the average value of user/passenger time (\$US or $€ / \mathrm{h}-\mathrm{pax}) ; S_{D}(\tau)$ is the schedule delay (min; h); and $P$ is the fare paid for a trip (\$US or $€ /$ pax).

The other symbols are analogous to those in Eq. 1d.

The schedule delay $(S D)$ in Eq. 5a is estimated based on an assumption that users/passengers arrive at the station/terminal at either side of the line/corridor uniformly distributed between any two successive train's departures during time $(\tau)$, as follows:

$$
S D(\tau)=1 / 2 \times \Delta[\tau / f(\tau)],
$$

where all symbols are as in the previous Eqs.

The fare $(P)$ paid for a trip in Eq. 5a can be set up to cover the total operating costs and also provide some profits for transport operators.

c) Users/passengers "welfare"

The users/passengers "welfare" expressed in savings of their generalized travel costs thanks to switching from the existing lower to the new higher speed system introduced along the given line/corridor can be estimated as follows:

$$
S c g_{i / j}(\tau)=Q_{i / j}(\tau) \times \Delta\left\{\beta_{i / j} \times\left[\left(S D_{i}+\Delta \tau_{l / i}\right)-\left(S D_{j}+\Delta \tau_{l / j}\right)\right]+\left(P_{i}-P_{j}\right)\right\},
$$

where $i, j$ is the existing lower speed and the new higher speed system, respectively; $Q_{i j j}$ is the volume of user/passenger demand switching from the existing lower speed system $(i)$ to the new higher system $(j)$ during time $(\tau)$ (pax/h, day, year); and $\beta_{i j /}$ is the average value of time of user/passenger switching from the existing system (i) to the new system ( $j$ ) ( $\$$ US or $€ /$ h-pax).

The other symbols are analogous to those in the previous Eqs.

d) Contribution to GDP

Contribution of each of three considered HS systems to the national GDP (Gross Domestic Product) is estimated as follows:

$$
R_{G D P}(\tau)=\frac{S_{r / G D P} \cdot G D P(\tau)}{T T W_{r / 2}(\tau)} \times T W_{2}(\tau),
$$

where $s_{r / G D P}$ is the relative contribution of domestic rail passenger transportation to the national GDP $(\leq 1.0) ; G D P(\tau)$ is the national GDP during time $(\tau)$ (\$US/ year); $T T W_{r / 2}(\tau)$ is the volume of domestic rail passenger transportation carried out 
during time $(\tau)(\mathrm{p}-\mathrm{km} / \mathrm{year}) ; T W_{2}(\tau)$ is the volume of rail passenger transportation carried out by the particular HS systems along the given line/corridor during time ( $\tau)(\mathrm{p}-\mathrm{km} /$ year);

\subsubsection{Environmental performances}

The indicators of environmental performances include the energy consumption and related emissions of GHG, and land use.

a) Energy consumption and emissions of GHG (Green House Gases)

The energy consumption and related emissions of GHG (Green House Gases) are considered exclusively from operations of vehicles/trains (HS and TRM trains, and the HL capsules) along the given corridor/line between its end stations/ terminals without the intermediate stops. This implies exclusion of the energy consumed for building the infrastructure (lines), and manufacturing the supporting facilities and equipment and rolling stock (trains) [17].

The energy consumption of the above-mentioned trains/capsules generally includes that for acceleration, cruising, and deceleration. The energy is generally consumed for overcoming the rolling, aerodynamic, gradient and, at the TRM and HL (Hyperloop) system, levitation force. As well, the energy is consumed for powering the equipment on board the trains. In particular, during the acceleration phase of a trip the electric energy is converted into the kinetic energy at an amount proportional to the product of the train's mass and the square of its speed(s). A part of this energy recovers during deceleration phase by means by the regenerative breaking before the train's stop. During the cruising phase of a trip, the trains mainly consume energy to overcome the rolling/mechanical and the aerodynamic resistance. The TRM and HL use energy all the time for levitating. Under such conditions, the total energy consumed by a train operating along the given line/corridor of the length $(L)$ in the single direction can be estimated as follows [18, 19]:

$$
E_{\text {TOT }}(L)=(1 / \eta) \times\left[E\left(l_{a}\right)+E\left(L-l_{a}-l_{d}\right)+E\left(l_{d}\right)\right],
$$

where $\eta$ is the efficiency of the given HS system's traction system $(\eta \leq 1.0) ; E\left(l_{a}\right)$, $E\left(l_{d}\right)$ is the energy consumption during the train's acceleration and deceleration phase of the non-stop trip, respectively $(J) ; E\left(L-l_{a}-l_{d}\right)$ is the energy consumption during the train's cruising phase of non-stop trip $(J) ; J$ is Joule $\left(\mathrm{kgm}^{2} / \mathrm{s}^{2}\right)$.

The particular components of Eq. 7a are estimated as follows:

$$
\begin{gathered}
E\left(l_{a}\right)=0.5 \times W_{T O T} \times v_{a}^{2}+\left(1-k_{0}\right) \times\left(1-k_{1}\right) \times W_{T O T} \times g \times h+ \\
+\left[\begin{array}{c}
k_{0} \times C_{R} \times W_{T O T} \times g+0.5 \times C_{L} \times \rho \times A \times\left(v_{a}+w\right)^{2}+ \\
+k_{1} \times W_{T O T} \times g \times \sin \alpha_{a}
\end{array}\right] \times l_{a}
\end{gathered}
$$




$$
\begin{gathered}
E\left(L-l_{a}-l_{d}\right)=\left(1-k_{0}\right) \times\left(1-k_{1}\right) \times W_{\text {TOT }} \times g \times h+ \\
+\left[\begin{array}{c}
k_{0} \times C_{R} \times W_{T O T} \times g+\frac{1}{2} \times C_{L} \times \rho \times A \times\left(v_{a}+w\right)^{2}+ \\
+k_{1} \times Q_{T O T} \times g \times \sin \alpha_{c} \\
\times\left(L-l_{a}-l_{d}\right)
\end{array}\right] \times \\
E\left(l_{d}=0.5 \times W_{T O T} \times\left(v_{a}-w\right)^{2}+\left(1-k_{0}\right) \times\left(1-k_{1}\right) \times W_{T O T} \times g \times h-\right. \\
-\left[k_{0} \times C_{R} \times Q_{T O T} \times g+0.5 \times C_{L} \times \rho \times A \times\left(v_{a}-w\right)^{2}+\right] \times l_{d}, \\
+k_{1} \times W_{T O T} \times g \times \sin \alpha_{d}
\end{gathered}
$$

where $W_{T O T}$ is the total mass of a vehicle/train (or HL capsule/pod) $(\mathrm{kg}) ; v_{a}, v_{c}, v_{d}$ is the speed of a vehicle/train (or HL capsule/pod) during acceleration, cruising, and deceleration, respectively $(\mathrm{m} / \mathrm{s}) ; C_{R}, C_{L}$ is the coefficient of rolling and aerodynamic resistance, respectively; $g$ is the gravitational constant $\left(\mathrm{m} / \mathrm{s}^{2}\right) ; \rho$ is the air density $\left(\mathrm{kg} / \mathrm{m}^{3}\right) ; A$ is the frontal area of a vehicle/train $\left(\mathrm{m}^{2}\right) ; \alpha_{a}, \alpha_{c}, \alpha_{d}$ is the gradient angle of the guideway (or HL tube) segments where acceleration, cruising, and deceleration are performed, respectively $\left({ }^{0}\right) ; L$ is the length of line $(\mathrm{m}) ; l_{a}, l_{d}$ is the acceleration and deceleration distance of a vehicle/train $(\mathrm{m}) ; w$ is the head wind $(\mathrm{m} / \mathrm{s}) ; h$ is the height of levitation of a TRM train or HL capsule above the floor of the guideway or tube, respectively $(\mathrm{m}) ; k_{0}, k_{1}$ is a binary variable taking the value " 1 " if a train/ vehicle is levitating (i.e., TRM and/or HL) and the value " 0 ", otherwise.

From Eq. 7a, the energy consumed per non-stop trip expressed in $(\mathrm{kWh} / \mathrm{s}-$ $\mathrm{km})$ is equal to:

$$
E(L)=\left[E_{T O T}(L)\right] \times 2.77778 \times 10^{-7},
$$

where $1 J=2.77778 \times 10^{-7} \mathrm{kWh}$.

From Eq. 7e, the emissions of GHG per trip along the given line/corridor in a single direction can be estimated as follows:

$$
E M_{G H G}(L)=E(L) \times E M R,
$$

where EMR is the emission rate of $\mathrm{GHG}\left(\mathrm{gCO}_{2 \mathrm{e}} / \mathrm{kWh}\right)$.

b) Land use

The infrastructure of the HSR, TRM, and HL system occupies the area of land taken for the lines and stations/terminals. The largest proportion of land is generally taken for building the lines (ha) and can be approximately estimated as follows:

$$
L U=L \times D,
$$


where $D$ is the width of cross-section of the line/corridor (m); $L$ is the length of a line/corridor $(\mathrm{m})$; $h a$ is hectare $\left(1 \mathrm{ha}=10 \cdot 10^{4} \mathrm{~m}^{2}\right)$.

\subsubsection{Social performances}

The indicators of social performances generally reflect:
a) Noise;
b) Congestion;
c) Traffic incidents/accidents (safety).
a) Noise

The noise of the HSR, TRM, and HL system can be primarily generated from three physical sources:

1) rolling noise (mainly the rail and track base vibration - HSR;

2) traction noise - HSR;

3) aerodynamic noise - HSR, TRM;

4) impact noise (from crossings, switches and junctions - HSR;

5) noise due to additional effects such as bridges - HSR. This implies that $\mathrm{HL}$ is free of noise due to any causes thanks to operating in the vacuumed tube. The experienced noise mainly depends on its level generated by the source, i.e., passing by trains (in this case HS and TRM trains), and their distance from an exposed population/observer(s). Therefore, the noise depending on the distance between a passing by train and the potentially affected observer(s) can be estimated as follows [20]:

$$
L_{A E}[r(t)]=L_{A E}(\gamma)-20 \log _{10}[r(t) / \gamma],
$$

where $t$ is the time of passing by trains at the distance $(r(t))$ and $(\gamma)(\min ) ; L_{A E}[r(t)]$, $L_{A E}(\gamma)$ is the noise from the source at the distances $r(t)$ and $(\gamma)$, respectively $(\mathrm{dBA})$; $\gamma$ is the reference right-angle distance between the measurement location and passing by train (usually $\gamma=25 \mathrm{~m}$ ); $r(t)$, is the distance between passing by train and an observer $(\gamma \leq r(t))(m)$.

b) Congestion

Thanks to the way of controlling successive trains operating simultaneously along the line/corridor, the HSR, TRM, and HL system are assumed to be free of congestion and consequent delays under regular operating conditions.

c) Traffic incidents/accidents (safety)

Similarly as at the road-based systems, the number of perceived incidents/ accidents of particular train-based systems operating between the catchment area (CDB) and the airport serving it during a given period of time can be estimated as follows:

$$
n_{a c}(\tau)=a c_{r} \times f(\tau) \times \theta \times S \times 2 L,
$$


where $a c_{r}$ is the train incident/accident rate (events, fatalities, injuries/p-km); $f(\tau)$ is the transport service frequency during time $(\tau) . S$ is the space capacity (seats/ spaces per departure); $L$ is the length of line/corridor $(\mathrm{km})$.

\subsection{The $\underline{\text { Simple }}$ Additive Weighting (SAW) and the entropy method}

The SAW multicriteria method is selected as the simplest and clearest method. It is often used as a benchmark for comparison of the results obtained from other discrete MCDMs (Multi Criteria Decision Making Method(s)) methods applied to the same problem. In general, the method requires the preselection of a discrete number of alternatives (three in this case) represented by the number of quantifiable (conflicting and non-commensurable) evaluation criteria of their performances. For the DM, particular criteria can reflect 'costs' and 'benefits'. In such a case, a larger outcome means a stronger preference for the 'benefit' and less preference for the 'cost' criterion [21,22].

The SAW method includes quantification of the values of indicators of performances and set up them as criteria for each alternative, construction of the Decision-Matrix $\boldsymbol{A}$ containing these values, derivation of the normalised decisionmatrix $\boldsymbol{R}$, setting up the importance (weights) to criteria, and calculation of the overall score for each alternative. Then, the alternative with the highest score is selected as the preferable (best) one. The analytical structure of the SAW method for $N$ alternatives and $M$ attributes (criteria) is as follows:

$$
S_{i}=\sum_{j=1}^{M} w_{j} \times r_{i j} \text { for } i=1,2, \ldots, N,
$$

where $S_{i}$ is the overall score of the $i$-th alternative; $r_{i j}$ is the normalised rating of the $i$-th alternative on the $j$-th criterion as an element of the normalised matrix $\boldsymbol{R}$; $w_{j}$ is the relative importance, i.e., weight of the $j$-th criterion; $N$ is the number of alternatives; $M$ is the number of criteria.

The normalised rating of the $i$-th alternative on the $j$-th criterion can be computed as follows:

$$
r_{i j}=x_{i j} /\left(\max _{i} x_{i j}\right) \text {, for the "benefit" criterion }
$$

and

$$
r_{i j}=\left(1 / x_{i j}\right) /\left[\max _{i}\left(1 / x_{i j}\right)\right] \text {, for the "cost" criterion }
$$

where $x_{i j}$ is an element of Decision-Matrix $\boldsymbol{A}$, which represents the "original" value of the $j$-th criterion of the $i$-th alternative.

The relative importance, i.e., weight of criteria in Eq. 10a can be estimated by the entropy method as follows [21]: 
If $\left(x_{i j}\right)$ is the the "original" value of the $j$-th criterion of the $i$-th alternative and an element of Decision-Matrix $\boldsymbol{A}$, the value $\left(p_{i j}\right)$ can be determined as follows:

$$
p_{i j}=x_{i j} / \sum_{i=1}^{N} x_{i j}, \text { for } j \in M
$$

Then, the entropy of the criterion $(j),\left(E_{j}\right)$ for $(N)$ alternatives can be expressed as follows:

$$
E_{j}=[-1 / \ln (N)] \times \sum_{i=1}^{N} p_{i j} \ln \left(p_{i j}\right), \text { for } j \in M
$$

where the term $[-1 / \ln (N)]$ provides fulfilment of the condition $0 \leq E_{j} \leq 1$.

If the Decision-Maker (DM) does not have a reason to prefer one criterion to the others, the weight of the criterion $(j)$ in Eq. 10a, $\left(w_{j}\right)$ can be determined as follows:

$$
w_{j}=\left(1-E_{j}\right) / \sum_{j=1}^{M}\left(1-E_{j}\right)
$$

\section{APPLICATION OF THE PROPOSED METHODOLOGY}

\subsection{Description of the case}

The proposed methodology is applied to the line/corridor between Moscow and Sank Petersburg (Russia). Currently, the corridor is served by the Sapsan HSR services operating at the maximum speed of: $v=250 \mathrm{~km} / \mathrm{h}$, taking an average of: $\Delta \tau_{l}=3.75 \mathrm{~h}$ to cover the distance of: $L=650 \mathrm{~km}$. The transport service frequency is: $f(\tau)=1 \mathrm{dep} / \mathrm{h}(\tau=1 \mathrm{~h})$, which gives the schedule delay of: $S D=1 / 2(60 / 1)=$ $30 \mathrm{~min}=0.5 \mathrm{~h}$. The average fare per trip is: $P=89$ \$US/pax-trip [23]. This HSR system is planned to be replaced by the exclusively built new HSR line of the length of: $L=660 \mathrm{~km}$ enabling operations of the HS trains at the maximum speed of $v=350 \mathrm{~km} / \mathrm{h}$. The same length would be of the alternative HS systems - TRM and HL, if considered. Accessibility of three systems from the corresponding urban areas would be the same since the begin-end stations/terminals would be located at the current rail stations (Moscow: Moscow Leningradsky also known as Moscow Passazhirskaya station, and St. Petersburg: St. Petersburg-Glavny rail station) [23]. The estimated volumes of users/passenger demand to be served in the given corridor exclusively by either system in the year 2030 would be: $Q=12.8 \times 10^{6}$ pax/ yr, or $q=(12.8 / 2) \times 10^{6 / 365} \approx 17534 \mathrm{pax} /$ day. These volumes implicitly imply the self-generated and attracted user/passenger demand, the later from the other transport modes - current HSR Sapsan, road, and air [24]. The simplified scheme of the line/corridor is shown on Fig. 6. 


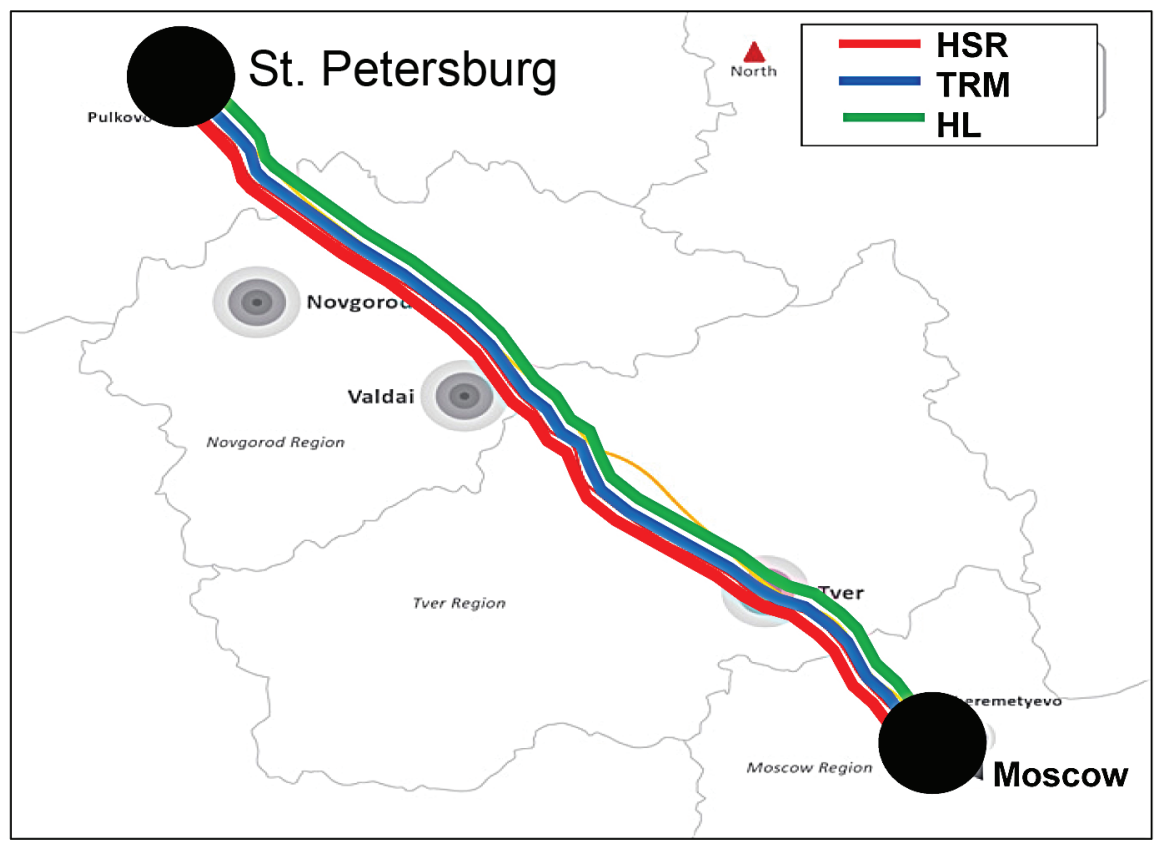

Fig. 6. Simplified scheme of the line/corridor Moscow-St. Petersburg (Russia) [24]

\subsection{Input data}

The inputs for estimating particular indicators of the operational, economic, environmental, and social performances influenced by the characteristics of infrastructure and rolling stock/fleet of vehicles/trains for three above-mentioned systems assumed to operate as the mutually exclusive alternatives along the given line/corridor connecting Moscow and St. Petersburg are given in Table 1. In

Table 1. Inputs on the characteristics of infrastructure and rolling stock/fleet of vehicles/ trains: Line/corridor: Moscow - Sankt Petersburg

\begin{tabular}{|l|c|c|c|}
\hline \multicolumn{1}{|c|}{ Input/System alternative } & HSR & TRM & HL \\
\hline Infrastructure & & & \\
\hline Line/corridor - length (km) [24, 25] & 660 & 660 & 660 \\
Stations/terminals - number per line/corridor & 2 & 2 & 2 \\
[24, 25] & 30 & 20 & 20 \\
Line traffic capacity (dep/h) [8] & & & \\
\hline Rolling stock/fleet of vehicles/trains & $10[26]$ & $5^{4)}$ & $2^{5)}$ \\
\hline Carriages per train & 670 & 292 & 30 \\
Gross weight (tons/train) & $8.0[26]$ & $25[15,10]$ & $21[12]$ \\
Propulsion (MW) & 12.7 & 15.4 & 3.9 \\
Frontal area (m²/train) & 604 & 449 & $2 \cdot 28$ \\
Capacity (seats/train-dep) & 300 & 400 & 1000 \\
Avg. operating speed (km/h) & 0.7 & 0.7 & 1.5 \\
Avg. acceleration/deceleration rate $\left(\mathrm{m} / \mathrm{s}^{2}\right)$ & & & \\
\hline
\end{tabular}


addition, the inputs for estimating indicators and the estimated indicators of the operational performances are given in Table 2 .

Table 2. Inputs for estimating and the estimated indicators of operational performances: Line/ corridor: Moscow - Sankt Petersburg

\begin{tabular}{|c|c|c|c|}
\hline Input/System alternative & HSR & TRM & HL \\
\hline \multicolumn{4}{|l|}{ Inputs } \\
\hline Demand $(\text { pax/day })^{1)}$ & 17534 & 17534 & 17534 \\
\hline Required service frequency (dep/day-dir) & 32 & 54 & 360 \\
\hline Time of operation of transport services (h/day) & 18 & 18 & 18 \\
\hline Required service frequency (dep/h-dir) & 2 & 3 & 20 \\
\hline Travel time per direction (non-stop) (h) & 2.23 & 1.69 & 0.71 \\
\hline Stop time at each end station/terminal (min) & 15 & 15 & 15 \\
\hline \multicolumn{4}{|l|}{ Estimates } \\
\hline Required rolling stock (vehicle units) ${ }^{2)}$ & 10 & 12 & 77 \\
\hline Transport work (p-km/h-dir) ${ }^{3)}$ & 717552 & 642761 & 643104 \\
\hline Technical productivity ( $\mathrm{p}-\mathrm{km} / \mathrm{h}^{2}$-dir) & 358776 & 389552 & 940800 \\
\hline Load factor & 0.90 & 0.72 & 0.87 \\
\hline
\end{tabular}

1) Based on the estimated annual number of passengers per direction: $\mathrm{Q}=12.8 \cdot 106 / 2=$ $6.4 \cdot 10^{6} \mathrm{pax} /$ year the vehicle/train seating capacity (pax - passengers) [24]; ${ }^{2)}$ For HL this is the number of capsules; for HS and TRM this is the number of train sets; ${ }^{3)} \mathrm{p}-\mathrm{km}$ - passenger kilometer; $\mathrm{h}$ - hour; dir - direction

The inputs for estimating indicators and the estimated indicators of the economic performances are given in Table 3.

Table 3. Inputs for estimating and the estimated indicators of economic performances: Line/ corridor: Moscow - Sankt Petersburg

\begin{tabular}{|c|c|c|c|}
\hline Input/System alternative & HSR & TRM & HL \\
\hline \multicolumn{4}{|l|}{ Inputs } \\
\hline Schedule delay $(\min )^{1)}$ & 15 & 10 & 1.5 \\
\hline Travel time per direction (non-stop) (h) & 2.23 & 1.69 & 0.71 \\
\hline Avg. unit operating costs (\$US/p-km) $[12,13,27,10]$ & 0.173 & 0.120 & 0.086 \\
\hline Value of user/passenger time (\$US/h) [28] & 33.08 & 33.08 & 33.08 \\
\hline Avg. fare $(\$ U S / p a x)^{2)}$ & 114 & 79 & 57 \\
\hline Contribution to GDP (\$US/p-km) $[29,30]$ & 0.00381 & 0.00381 & 0.00381 \\
\hline \multicolumn{4}{|l|}{ Estimates } \\
\hline Operating costs $\left(10^{6} \$ \mathrm{US} /\right.$ year $)$ & 805.508 & 700.903 & 417.663 \\
\hline Generalized user's/passenger's costs (\$US/trip) & 196.04 & 140.42 & 81.31 \\
\hline User/passenger "welfare" $\left(10^{6} \$ \text { US/year }\right)^{3)}$ & 0.588 & 1.562 & 2.600 \\
\hline Contribution to GDP $\left(10^{6} \$ \mathrm{US} / \text { year }\right)^{4)}$ & 36.590 & 32.179 & 32.196 \\
\hline
\end{tabular}

1) Based on the transport service frequency; ${ }^{2)}$ Based on covering the average operating costs ( $\mathrm{p}-\mathrm{km}$ - passenger kilometre; pax - passenger; $\mathrm{h}$ - hour); ${ }^{3)}$ Savings in the generalized user/ passenger costs compared to the currently operating HS Sapsan trains [23]; ${ }^{4)}$ Both directions. 
The inputs for estimating indicators and the estimated indicators of the environmental and social performances are given in Table 4.

Table 4. Inputs for estimating and the estimated indicators of environmental and social performances: Line/corridor: Moscow - Sankt Petersburg

\begin{tabular}{|c|c|c|c|}
\hline Indicator /System alternative & HSR & TRM & HL \\
\hline \multicolumn{4}{|l|}{ Inputs } \\
\hline \multicolumn{4}{|l|}{ - Environmental } \\
\hline Energy consumption (Wh//s-km) & $51[31,32]$ & $52[31,32]$ & $28.4^{1)}$ \\
\hline Emissions of GHG $\left(\mathrm{gCO}_{2} / \mathrm{s}-\mathrm{km}\right)[33,34]$ & 487 & 487 & 487 \\
\hline $\begin{array}{l}\text { Land use (width of right-of-way ) (m) } \\
{[9,31,12]}\end{array}$ & 25 & 17 & $6[12]$ \\
\hline \multicolumn{4}{|l|}{ - Social } \\
\hline Noise $(\mathrm{dB}(\mathrm{A}))^{2)}$ & 90.5 & 88.5 & 0 \\
\hline Congestion (-) & Free & Free & Free \\
\hline $\begin{array}{l}\text { Traffic incidents/accidents (safety) } \\
\text { (fatalities/pkm-year) }\end{array}$ & 0 & 0 & 0 \\
\hline \multicolumn{4}{|l|}{ Estimates } \\
\hline \multicolumn{4}{|l|}{ - Environmental } \\
\hline Energy consumption $\left(10^{3} \mathrm{kWh} /\right.$ day-dir $)$ & 650.558 & 832.123 & 377.480 \\
\hline Emissions of $\mathrm{GHG}$ (tonCO $\mathrm{CO}_{2} /$ day-dir) & 316.836 & 405.249 & 183.833 \\
\hline Land use (ha) & 1650 & 1122 & 396 \\
\hline \multicolumn{4}{|l|}{ - $\underline{\text { Social }}$} \\
\hline Noise $(\mathrm{dB}(\mathrm{A}))^{2)}$ & 90.5 & 88.5 & 0 \\
\hline Congestion $(-)^{3)}$ & 0 & 0 & 0 \\
\hline $\begin{array}{l}\text { Traffic incidents/accidents (safety) } \\
\text { (fatalities/p-km-year) }\end{array}$ & 0 & 0 & 0 \\
\hline
\end{tabular}

1) Own calculations by Eq. 7 under assumption that HL would use electricity from the national electricity system and not from the solar panels due to prevailing weather/climate along the line/ corridor (the energy consumed for vacuuming the tubes is not included) $;{ }^{2)}$ By trains passing at the right-angle distance of $25 \mathrm{~m}$ at the speed of $v=300 \mathrm{~km} / \mathrm{h}$ (HSR), and $400 \mathrm{~km} / \mathrm{h}$ (TRM) [31];

3) Free of congestion

The estimated values of particular indicators of performances in Tables 2-4 are summarized in Table 5 as the final input for application of the above-mentioned SAW multicriteria evaluation method.

As can be seen, of the total 14 criteria, 5 have appeared as the "benefit" and the remaining 9 as the "cost" criteria.

\subsection{Analysis of results}

The results from application of the multicriteria evaluation methodology to the given case are given in Table 6. 
Table 5. Summary of the estimated indicators of performances of the three HS alternatives used as evaluation criteria in the given example: Line/ corridor: Moscow - Sankt Petersburg

\begin{tabular}{|c|c|c|c|c|}
\hline \multirow{2}{*}{ Indicator/criteria } & \multirow{2}{*}{$\begin{array}{c}\text { Type } \\
\text { (Orientation) }\end{array}$} & \multicolumn{3}{|c|}{ System/alternative } \\
\hline & & HSR & TRM & HL \\
\hline \multicolumn{5}{|l|}{ - Operational } \\
\hline Required rolling stock (vehicle units) & - & 10 & 12 & 77 \\
\hline Transport work (p-km/h-dir) & + & 717552 & 642761 & 643104 \\
\hline Technical productivity ( $\mathrm{p}-\mathrm{m} / \mathrm{h}^{2}$-dir) & + & 358776 & 389552 & 940800 \\
\hline Load factor $(-)$ & + & 0.90 & 0.72 & 0.87 \\
\hline \multicolumn{5}{|l|}{ - Economic } \\
\hline Operating costs ( $10^{6} \mathrm{US} /$ year $)$ & - & 805.508 & 700.903 & 417.663 \\
\hline $\begin{array}{l}\text { Generalized user/passenger costs (\$US/ } \\
\text { trip) }\end{array}$ & - & 196.04 & 140.42 & 81.31 \\
\hline $\begin{array}{l}\text { Users/passengers “welfare” ( } 10^{6} \$ \mathrm{US} / \\
\text { year) }\end{array}$ & + & 0.588 & 1.562 & 2.600 \\
\hline Contribution to GDP $\left(10^{6} \$ \mathrm{US} /\right.$ year $)$ & + & 36.590 & 32.179 & 32.196 \\
\hline \multicolumn{5}{|l|}{ - Environmental } \\
\hline Energy consumption $\left(10^{3} \mathrm{kWh} /\right.$ day-dir $)$ & - & 650.558 & 832.123 & 377.480 \\
\hline Emissions of $\mathrm{GHG}$ (ton $\mathrm{CO}_{2} /$ day-dir) & - & 316.836 & 405.249 & 183.833 \\
\hline Land use (ha) & - & 1650 & 1122 & 396 \\
\hline \multicolumn{5}{|l|}{ - $\underline{\text { Social }}$} \\
\hline Noise (dBA/passing by train) & - & 90.5 & 88.5 & 0 \\
\hline Congestion (-) & - & 0 & 0 & 0 \\
\hline $\begin{array}{l}\text { Traffic incidents/ accidents (safety) } \\
\text { (fatalities } / \mathrm{p}-\mathrm{km} \text { ) }\end{array}$ & - & 0 & 0 & 0 \\
\hline
\end{tabular}

“-” $\equiv$ “cost” criterion; “+”” "benefit” criterion

As can be seen, according to the assumed "what-if" scenario, the most important criteria (with the highest weights) have been the 'required rolling stock', 'noise', and 'users/passengers "welfare"'. The least important have appeared to be the 'transport work', 'contribution to GDP', and 'load factor'. Due to the nature of operations and the lack of comparable data the criteria 'congestion' and 'traffic incidents/accidents (safety), respectively, have not been weighted. As a result, overall the HL system has scored the highest followed by the TRM and HSR system. The latest has scored the lowest. However, the difference between the scores of TRM and HSR system has been marginal. The number of the highest nominal rates $\left(r_{i j}=1\right)$ has conditioned such score. It has been the highest for HL6 criteria (technical productivity, operating costs, generalized user/passenger costs, energy consumption and emissions of GHG and noise), and for HSR - 3 criteria (required rolling stock, transport work and contribution to GDP). The TRM system 
Table 6. Results from application of the multicriteria evaluation methodology to the given case: Line/corridor: Moscow - Sankt Petersburg

\begin{tabular}{|c|c|c|c|c|}
\hline \multirow[t]{3}{*}{ Indicator/criterion $(j)$} & \multirow{3}{*}{$\begin{array}{l}\text { Weight of } \\
\text { criterion } \\
(j) \\
\left(w_{i}\right)\end{array}$} & \multirow{2}{*}{\multicolumn{3}{|c|}{$\begin{array}{c}\text { Normalized rates } \\
\left(r_{i j}\right)\end{array}$}} \\
\hline & & & & \\
\hline & & HSR & TRM & HL \\
\hline \multicolumn{5}{|l|}{ - Operational } \\
\hline Required rolling stock (vehicle units) & 0.302885 & 1.00000 & 0.83333 & 0.12987 \\
\hline Transport work (pax-km/h-dir) & 0.001119 & 1.00000 & 0.89580 & 0.89600 \\
\hline Technical productivity ( $\mathrm{pax}-\mathrm{km} / \mathrm{h}^{2}$-dir) & 0.076720 & 0.38100 & 0.41400 & 1.00000 \\
\hline Load factor $(-)$ & 0.003396 & 1.00000 & 0.80000 & 0.96700 \\
\hline \multicolumn{5}{|l|}{ - Economic } \\
\hline Operating costs ( $10^{6} \$ \mathrm{US} /$ year) & 0.028858 & 0.51851 & 0.59600 & 1.00000 \\
\hline Generalized user/passenger cost (\$US/trip) & 0.042596 & 0.41500 & 0.57900 & 1.00000 \\
\hline Users/passengers "welfare" ( $10^{6} \$$ US/year $)$ & 0.104771 & 0.26000 & 0.60000 & 1.00000 \\
\hline Contribution to GDP $\left(10^{6} \$ \mathrm{US} /\right.$ year $)$ & 0.001598 & 1.00000 & 0.87940 & 0.87990 \\
\hline \multicolumn{5}{|l|}{ - Environmental } \\
\hline Energy consumption $\left(10^{3} \mathrm{kWh} /\right.$ day-dir $)$ & 0.034604 & 0.58000 & 0.45400 & 1.00000 \\
\hline Emissions of $\mathrm{GHG}$ (tonCO $\mathrm{C}_{2} /$ day-dir) & 0.034604 & 0.58000 & 0.45400 & 1.00000 \\
\hline Land use (ha) & 0.095900 & 0.24000 & 0.35300 & 1.00000 \\
\hline \multicolumn{5}{|l|}{ - Social } \\
\hline Noise (dBA)/passing by train) & 0.279916 & 0.01000 & 0.01130 & 1.00000 \\
\hline Congestion (-) & 0 & 0 & 0 & 0 \\
\hline $\begin{array}{l}\text { Traffic incidents/accidents (safety) } \\
\text { (fatalities/pkm) }\end{array}$ & 0 & 0 & 0 & 0 \\
\hline$\sum_{j=1}^{M} w_{j}$ & 1.00000 & & & \\
\hline$S_{i}=\sum_{j=1}^{M} w_{j} \cdot r_{i j}$ & & 0.46052 & 0.46239 & 0.49041 \\
\hline
\end{tabular}

has not have any nominal rate equal to one. Consequently, the main reasons for the HL system to score the best have seemed to be its overall lower operating costs, superior transport service frequency and operating speed benefiting to the user/ passenger generalized travel costs, and a complete lack of the noise impact thanks to operating within the closed environment (tube). However, this score should be taken into account with caution. This is because estimation of the indicators of performances as criteria has been based just on the conceptual design of HL still not being operational anywhere. This implies a high uncertainty in the expected performances if the system would be implemented particularly in the given case. 
The similar relates to the TRM system, which has been in the commercial use at the very limited scale (Shanghai Pudong International Airport connecting Longyang Road Station in the outskirts of central Pudong of the short route compared to the considered case $-30.5 \mathrm{~km}$ ) [25]. Additional uncertainty not being included in the above-mentioned evaluation of both these systems is their robustness (i.e., resilience) to the impacts of different external and internal disruptive events (extreme weather, failures of components, and managing recoveries). Therefore, the most objective assessment of indicators of performances has been for the HSR operating at the very large scale worldwide including in the given case.

The additional question is about the 'credibility' of the proposed MCDM (Multi Criteria Decision Making) method for the DMs involved. The experience so far has shown that application of the other methods such as TOPSIS (Technique for Order Preference by Similarity to the Ideal Solution), AHP (Analytic Hierarchy Process), DEA (Data Envelopment Analysis), and ELECTRE (ELimination Et Choix Traduisant la REalit'e - ELimination and Choice Expressing the REality) to the similar cases has produced the identical ranking scores. As well, application of the CBA method should not be neglected just for checking the overall financial feasibility of the considered alternatives as the support of the choice of the referable one. However, in any case, DMs should count on the rather "fuzziness" of inputs for estimating indicators of performances of the systems still at the very rough conceptual stage like the HL system is.

\section{CONCLUSIONS}

This paper has dealt with the multicriteria evaluation of the High Speed Rail (HSR), TransRapid Maglev (TRM) and Hyperloop (HL) passenger transport system assumed to operate as the mutually exclusive alternatives in the given line/ corridor. For such a purpose, the methodology consisting of the analytical models of indicators of their performances used as criteria, the SAW (Simple Additive Weighting) method, and the entropy method for estimating the relative importance, i.e., weights, of particular criteria has been synthesized. The methodology has been applied to ranking the above-mentioned three HS systems assumed to operate as the mutually exclusive alternatives along the line/corridor Moscow - St. Petersburg (Russia). Given the characteristics of the infrastructure and rolling stock/fleet of vehicles, the fourteen indicators of the operational, economic, environmental, and social performances have been estimated based on a "what-if' scenario approach and then used as the evaluation criteria by the proposed Multi Criteria Decision making (MCDM) Method. The selected indicators of performances have aimed to reflect interests and preferences of particular DMs such could be direct systems' 
users/passengers, transport operators, local, regional, and national authorities and investors, and community members.

The results have indicated that the HL system would perform as the preferable alternative under given conditions, followed by TRM and HSR system. Nevertheless, despite showing usefulness as a support to the Decision Making (DM) process, at least regarding the consistency of the approach, the proposed approach would need additional checking by using more reliable input data for quantification of particular indicators of performances, the strongest for the HL systems, which is still at the highly conceptual stage of elaboration. This raises the issues for the further research, which generally should contribute to the reliability of outcome(s) from MCDM evaluation. Therefore, the additional research could deal with the issues as follows:

- Consolidating additionally the quality of inputs for estimating indicators of performances, particularly for the HL and TRM system while operating along the long-haul lines/corridors;

- Widening the set of "what-if" operating scenarios by including those where the three HS systems would stop at the intermediate stops/stations and also compete with each other;

- Extending the set of indicators of performances by including more details for example those related to resilience of three systems when being impacted by different external and internal disruptive events (if available);

- Evaluating the three HS systems by using other MCDM methods and the CBA as well; and last but not least

- Expanding the set of considered alternatives by including the fourth HS system - APT (Air Passenger Transport) - and then evaluating them under the above-mentioned conditions.

\section{References}

1. Janić M. Advanced Transport Systems: Analysis, Modelling, and Evaluation of Performances. UK: SpringerVerlag; 2014.

2. Feigenbaum B. High-Speed Rail in Europe and Asia: Lessons for the United States, Reason Foundation, Policy Study 418, USA: Los Angeles, CA; 2013.

3. Janić M. Multicriteria Evaluation of High-Speed Rail, Transrapid Maglev and Air Passenger Transport Systems in Europe. Transportation Planning and Technology. 2003;26(6):491-512. doi: $10.1080 / 0308106032000167373$

4. Vuchic RV, Casello MJ. An Evaluation of Maglev Technology and Its Comparison with High Speed Rail. Transportation Quarterly. 2002;56(2):33-49

5. Campos J, de Rus G. Some Stylized Facts about High-Speed Rail: A Review of HSR Experiences around the World. Transport Policy. 2009;16:19-28. doi: 10.1016/j.tranpol.2009.02.008

6. EC. Interoperability of the Trans-European High Speed Rail System, Directive 96/48/EC, European Commission, Brussels, Belgium; 1996. p. 155

7. Janić M. A Multidimensional Examination of the Performances of HSR (High Speed Rail) Systems. Journal of Modern Transportation. 2016;21(1):1-24. doi: 10.1007/s40534-015-0094-y

8. Janić M. Landside Accessibility of Airports. Berlin: Springer; 2018. 
9. Schach R, Naumann R. Comparison of High Speed Transportation Systems in Special Consideration of Investment Costs. Transport. 2007;22(3):139-147.

10. USDT. Costs and Benefits of Magnetic Levitation: Report to Congress, Federal Railroad Administration, U. S. Department of Transportation, Washington, D.C., USA, 2005.

11. Shanghai Maglev Train (SMT) [cited 2018 December 12]. Available at: https://www.travelchinaguide.com/ cityguides/shanghai/getting-around.htm/.

12. Musk E. Hyperloop Alpha, Texas: SpaceX [cited 2018 December 12]. Available at: http://www.spacex.com/ sites/spacex/files/hyperloop_alpha-20130812.pdf.

13. Taylor CT, Hyde DJ, Barr LC. Hyperloop Commercial Feasibility Analysis: High Level Overview, Volpe National Transportation research Centre, U.S. Department of Transportation, Cambridge MA, USA. 2016.

14. Wendell C, Vranich J. The California High Speed Rail Proposal: A Due Diligence Report, Reason Foundation. Los Angeles, California, USA (2008.

15. Cassat A, Bourquin V. MAGLEV - Worldwide Status and Technical Review. Proceedings of the Conference "Électrotechnique du Futur" 2011 Décembre 14-15; Belfort, France; 2011.

16. Vuchic RV. Urban Transit Systems and Technology. Wiley, New York, USA; 2007.

17. UIC. High Speed, Energy Consumption and Emissions. UIC Publications. International Union of Railways, Paris, France; 2010.

18. Jong JC, Chang FE. Models for Estimating Energy Consumption of Electric Trains. Journal of the Eastern Asia Society for Transportation Studies. 2005;6:278-291.

19. Rochard PB, Schmid F. A Review of Methods to Measure and Calculate Train Resistances. Proceedings of the Institute of Mechanical Engineering Part F. 2000;214:185-143. doi: 10.1243/0954409001531306

20. Teodorovic D, Janić M. Transportation Engineering: Theory, Practice and Modelling. Amsterdam: Elsevier; 2016.

21. Hwang LC, Yoon K. Multi Attribute Decision-Making: A Methods and Applications, Lecture Series in Economics and Mathematical Systems. Berlin: Springer-Verlag; 1981.

22. Zanakis SH, Solomon A, Wishart N, Dublish S. Multi-attribute Decision Making: A Simulation Comparison of Selected Methods. European Journal of Operational Research. 1998;107:507-529. doi: 10.1016/s03772217(97)00147-1

23. Sapsan high-speed train tickets [cited 2018 December 12]. Available at: https:/www.russiantrain.com/ sapsan?gclid/aAnNCEALw_wcB/.

24. RG (2011), "PPP Model to Fund Moscow-St. Petersburg High Speed Line", Railway Gazette, http://www. railwaygazette.com/news/single-view/view/ppp-model-to-fund-moscow-st-petersburg-high-speed-line.Html.

1. RR. High-Speed Trains", Russian Railways [cited 2017 June 3]. Available at: http://eng.rzd.ru/statice/public/ rzdeng?STRUCTURE_ID=4054. 25.

26. Siemens AG. High Seed Trainset Velaro RUS for Russian Railways (RZD). Industry Sector, Mobility Division, Public Transit, Erlangen, Germany; 2012.

27. UIC. Relationship between Rail Service Operating Direct Costs and Speed. International union of Railways, Paris, France; 2010.

28. Wardman M, Chintakayala P, de Jong G, Ferrer D. European Wide Meta-analysis of Values of Travel Time. Final Report to the European Investment Bank. UK: University of Leeds; 2012.

29. RR. Annual Report 2016, Russian Railways, Moscow, Russia.

30. Russia: Gross domestic product (GDP) in current prices from 2012 to 2022 (in billion U.S. dollars) [cited 2017 June 3]. Available at: https:/www.statista.com/statistics/263772/gross-domestic-product-gdp-in-russia/.

31. TKTA. ThyssenKrupp Transrapid Australia Submission in response to East West Link Needs Assessment report "Investing in Transport". ThyssenKrupp Transrapid Australia, ThyssenKrupp Transrapid Gmbh, Kassel, Germany; 2008.

32. UIC. High Speed Rail: Fast Track to Sustainable Mobility. International Union of Railways. Paris, France; 2010.

33. WNA. Comparison of Lifecycle Greenhouse Gas Emissions of Various Electricity Generation Sources, WNA Report World Nuclear Association, London, UK; 2011.

34. Global energy data at your fingertips [cited 2018 December 12]. Available at: http:/www.iea.org/statistics/ html/.

35. Shanghai maglev train [cited 2018 December 12]. Available at: https://en.wikipedia.org/wiki/Shanghai_ maglev_train.

Milan Janić,

ORCID: 0000-0003-4917-467X

E-mail: m.janic@tudelft.nl

To cite this article:

Janić M. Multicriteria Evaluation of the High Speed Rail, Transrapid Maglev and Hyperloop Systems. Transportation Systems and Technology. 2018;4(4):5-31. doi: 10.17816/transsyst2018445-31 